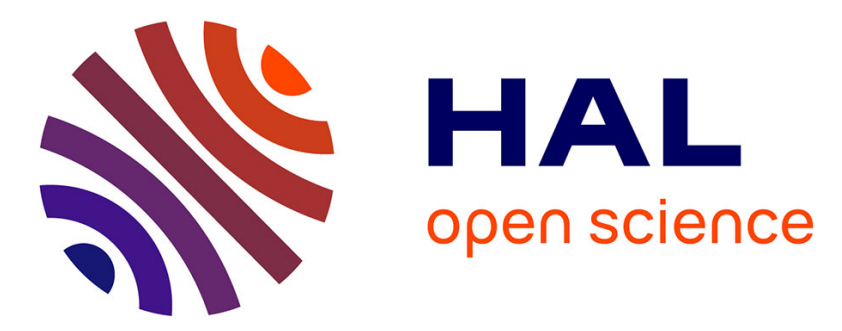

\title{
Proportioning and characterization of lightweight concrete mixtures made with rigid polyurethane foam wastes
}

Pierre Mounanga, W. Gbongbon, Philippe Poullain, Ph Turcry

\section{To cite this version:}

Pierre Mounanga, W. Gbongbon, Philippe Poullain, Ph Turcry. Proportioning and characterization of lightweight concrete mixtures made with rigid polyurethane foam wastes. Cement and Concrete Composites, 2008, 30 (9), pp.806-814. 10.1016/j.cemconcomp.2008.06.007 . hal-01007225

\section{HAL Id: hal-01007225 \\ https://hal.science/hal-01007225}

Submitted on 22 Nov 2018

HAL is a multi-disciplinary open access archive for the deposit and dissemination of scientific research documents, whether they are published or not. The documents may come from teaching and research institutions in France or abroad, or from public or private research centers.
L'archive ouverte pluridisciplinaire HAL, est destinée au dépôt et à la diffusion de documents scientifiques de niveau recherche, publiés ou non, émanant des établissements d'enseignement et de recherche français ou étrangers, des laboratoires publics ou privés.

\section{()ㅜ(1)}

Distributed under a Creative Commons Attribution - NonCommerciall 4.0 International 


\title{
Proportioning and characterization of lightweight concrete mixtures made with rigid polyurethane foam wastes
}

\author{
P. Mounanga ${ }^{\mathrm{a}, *}$, W. Gbongbon ${ }^{\mathrm{a}}$, P. Poullain ${ }^{\mathrm{a}}$, P. Turcry $^{\mathrm{b}}$ \\ ${ }^{a}$ Research Institute in Civil Engineering and Mechanics - GeM, UMR CNRS 6183, University of Nantes, IUT Saint-Nazaire, 58 rue Michel Ange, 44606 Saint-Nazaire cedex, France \\ ${ }^{\mathrm{b}}$ LEPTAB, University of La Rochelle, Avenue Michel Crépeau, 17042 La Rochelle cedex 01, France
}

\begin{abstract}
This paper presents the results of an experimental study concerning the incorporation of polyurethane (PUR) foam wastes into cementitious mixtures in order to produce lightweight concrete. A semi-empirical method is first proposed to predict the density of fresh PUR foam-based concrete mixtures. Seven concrete mixtures containing various PUR foam volume fractions (from $13.1 \%$ to $33.7 \%$ ), and two reference concrete mixtures (without PUR foam) were prepared and characterized. In particular, their thermal and mechanical properties were determined. This permitted to quantify the influence of the PUR foam volume fraction on these parameters. Some specimens were maintained under water during 28 days, while the others were dried in air. The PUR-foam concrete thermal conductivity and compressive strength are, respectively, 2-7 times and 2-17 times lower than those of the reference mixture, depending on the volume fraction of PUR foam and on the curing conditions. Besides, the use of PUR foam in concrete implies a strong increase in the drying shrinkage and in the mass loss during the first seven days. These results can be related to the high porosity and the weak compressive strength of alveolar polyurethane.
\end{abstract}

\section{Introduction}

Polyurethane (PUR) is one of the larger polymer product groups within the plastics family. In Europe, PUR consumption is about 3 million tons per year for the early 21 st century. It is composed of about 1.8 million tons flexible PUR foam, 0.7 million tons rigid PUR foam and 0.4 million tons PUR elastomer and other products [1]. Each year, plastic and modular construction industries generate huge volumes of PUR wastes during the fabrication, the conditioning and the use of these materials. Sustainable development and environmental management require taking into account these wastes. In Europe, total PUR waste is estimated to be about 1.5 million tons in 2004, approximately half of which is not suitable for collection and subsequent recycling, because of small volumes and/or wide distribution [2]. Recycling and specific valorisation methods have to be developed to deal with this problem.

Manufacture, working and destruction of rigid polyurethane (PUR) foam panels used for building wall insulation produce many low density particles and shavings. These wastes can be recycled in energy production plants [3] or building composites [4,5]. The incorporation of such materials into lightweight concrete could also be an interesting alternative for the valorisation of polyurethane foam wastes.

\footnotetext{
* Corresponding author. Tel.: +332401786 04; fax: +33240178160. E-mail address: pierre.mounanga@univ-nantes.fr (P. Mounanga).
}

From this viewpoint, a laboratory study has been carried out in order to determine the influence of PUR foam wastes, considered as lightweight aggregates, on the thermal conductivity, the volumetric heat capacity, the mechanical strength and the drying shrinkage of lightweight concrete.

Previous studies have been dedicated to the use of alveolar plastic wastes in the manufacture of lightweight concrete. Laukaitis et al. [6] used polystyrene foam wastes to produce insulating concrete. Considering cement/foam ratios varying from 1 to 3 , lightweight concretes with density ranging between 200 and 300 $\mathrm{kg} / \mathrm{m}^{3}$ were obtained, while the compressive strength ranged from 0.1 to $0.5 \mathrm{MPa}$ and the thermal conductivity from 0.07 to $0.1 \mathrm{~W} / \mathrm{m}$ K. Perevozchikov et al. [7] produced lightweight concretes including polyethylene foam wastes with a volume fraction of $30 \%$. By varying the water and cement contents, they obtained lightweight concrete with density between 1592 and $1840 \mathrm{~kg} / \mathrm{m}^{3}$ and compressive strength from 2.31 to $8.44 \mathrm{MPa}$.

The use of solid alveolar foam as lightweight aggregate makes it difficult to predict the material density. Indeed, PUR foam is a compressible material and exhibits high porosity, contrary to mineral aggregates such as sand or gravel. The water absorption $[8,9]$ and cement paste absorption [10] by the aggregates and the compressibility of foam yield greater density than the expected theoretical one. This is different for classical concrete mixture whose real density is always lower than the theoretical density, in particular because of the trapped air during mixing. A previous study about PUR-foam mortars [11], showed that the real volume of mixture 
can be $20-40 \%$ lower than that of the expected volume. This could result in an overestimation of the need in cement and an expensive concrete composition.

The first part of this paper is dedicated to the characterization of polyurethane foam wastes and to the development of a predictive model for the packing and bulk densities of PUR-foam concrete.

Two series of PUR-foam concrete mixtures, with and without limestone filler, and containing different PUR-foam contents are investigated. The mechanical and thermophysical properties, the drying shrinkage and the mass loss of these mixtures are measured and compared with the same properties of a reference mixture (without PUR foam).

\section{Concrete components}

\subsection{Cement}

The cement used in this study is CEM II/B-LL 32.5R CE NF from Saint Pierre La Cour plant (France). Its density is $3050 \mathrm{~kg} / \mathrm{m}^{3}$ and its Blaine fineness of $395 \mathrm{~m}^{2} / \mathrm{kg}$. It is constituted of $75 \%$ of clinker and $24 \%$ of limestone. Its chemical composition is given in Table 1.

\subsection{Limestone filler}

The limestone filler is Betocarb ${ }^{\mathrm{TM}} \mathrm{P} 2$ from Erbray plant (France). It contains $98.4 \%$ of calcium carbonate. Its density is $2714 \mathrm{~kg} / \mathrm{m}^{3}$ and its specific area is $397 \mathrm{~m}^{2} / \mathrm{kg}$. Its particle size distribution, given by the manufacturer, is presented on Fig. 1.

\subsection{Sand}

The sand is a river sand sieved between 0 and $5 \mathrm{~mm}$. Its density is $2650 \mathrm{~kg} / \mathrm{m}^{3}$. Its particle size distribution, obtained according to the French standard NF P18-560 [12], is provided on Fig. 1.

Table 1

Cement chemical composition

\begin{tabular}{lr}
\hline Components & Mass\% \\
\hline Calcium oxide $(\mathrm{CaO})$ & 62.00 \\
Silica $\left(\mathrm{SiO}_{2}\right)$ & 15.90 \\
Alumina $\left(\mathrm{Al}_{2} \mathrm{O}_{3}\right)$ & 3.90 \\
Ferric oxide $\left(\mathrm{Fe}_{2} \mathrm{O}_{3}\right)$ & 2.15 \\
Potassium oxide $\left(\mathrm{K}_{2} \mathrm{O}\right)$ & 0.80 \\
Magnesium oxide $(\mathrm{MgO})$ & 0.80 \\
Sodium oxide $\left(\mathrm{Na}_{2} \mathrm{O}\right)$ & 0.14 \\
Sulphuric anhydride $\left(\mathrm{SO}_{3}\right)$ & 2.65 \\
Free lime & 0.84 \\
Loss on ignition & 11.05 \\
\hline
\end{tabular}

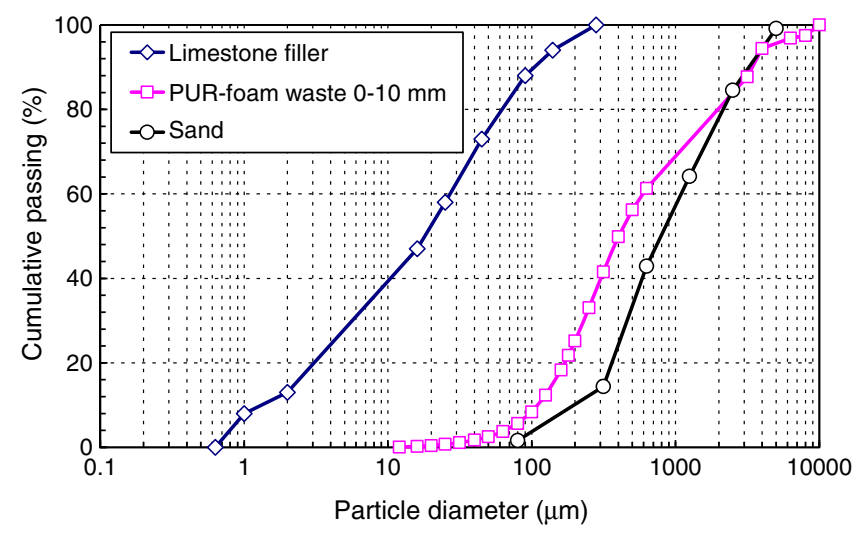

Fig. 1. Particle size distributions of limestone filler, PUR foam wastes and sand used.

\subsection{Polyurethane foam wastes}

Polyurethane foam wastes come from the destruction of insulation panels used in building industry. They were provided by a manufacturer of insulation panels, in two different big bags: a big bag containing "coarse" waste, with a size greater than $10 \mathrm{~mm}$ and a big bag containing "fine" waste, very rich in fine particles and with a size lower or equal to $10 \mathrm{~mm}$ (Fig. 2). The terms of "coarse" and "fine" aggregates do not match with the classical definitions of ASTM standards and are only used to differentiate the two forms of wastes. Only the second grade ("fine" aggregates) is studied here. The particle size distribution is given on Fig. 1. It was obtained by combining results from laser granulometry (0/2$\mathrm{mm}$ particles) and sieving granulometry ( $2 / 10-\mathrm{mm}$ particles). The particle diameters range on a wide interval and the waste fineness has to be noted ( $68 \%$ of the whole product volume is composed of particles with a diameter lower than $2 \mathrm{~mm}$ ).

The apparent density of the PUR foam, $\rho_{\text {PUR foam, has been mea- }}$ sured on three cubic samples. This density has been evaluated to be $45 \pm 2 \mathrm{~kg} / \mathrm{m}^{3}$ and is of the same order of magnitude than that given by the panel supplier $\left(40 \mathrm{~kg} / \mathrm{m}^{3}\right)$. According to the product specification sheet, the foam porosity $n$ is equal to $98 \%$. This density corresponds to the mechanically unloaded dry foam. From these data, the density of plain polyurethane $\rho_{\text {PUR }}$ (without porosity) can be estimated with the following relation:

$\rho_{\text {PUR }}=\frac{\rho_{\text {PUR foam }}-n \times \rho_{\text {air }}}{1-n}$,

where $\rho_{\text {PUR foam }}$ is the PUR-foam apparent density $\left(\mathrm{kg} / \mathrm{m}^{3}\right), \rho_{\text {air }}$ the air density at $20^{\circ} \mathrm{C}\left(1.2 \mathrm{~kg} / \mathrm{m}^{3}\right)$ and $n$ the PUR-foam porosity (-).

The density of PUR, $\rho_{\text {PUR, }}$, is about $2191 \mathrm{~kg} / \mathrm{m}^{3}$. This value will be used later in this paper to estimate the absolute density of PURfoam concrete.

SEM observation (Fig. 3) shows the open porosity of foam aggregates. The pores are cavities of about $200-\mu$ m diameter. This information is of great importance in estimating the absorption capacity of cement paste by these lightweight aggregates.

\section{Mix-proportioning of PUR-foam concrete}

\subsection{Workability}

The first mix-design criterion studied is the workability of the prepared mixtures with the aim of obtaining plastic mixtures. The open porosity and the fineness of the polyurethane foam particles require relatively high $\mathrm{W} / \mathrm{C}$ ratios to ensure a good workability (see Table 2). Series II was specifically designed in order to obtain mixtures with comparable workabilities and cement proportions. The incorporation of an important PUR-foam volume in replacement of sand requires increasing the $\mathrm{W} / \mathrm{C}$ ratio to keep workability close to that of the reference mixture. From this point of view, the use of a reducing water agent could constitute an interesting alternative.

\subsection{Compressibility and absorption of the PUR-foam aggregates}

The lightweight aggregate compression and paste absorption make it difficult to predict the effective volume of concrete [10]. These phenomena, schematized on Fig. 4, lead to a bulk volume of the freshly-prepared concrete quite lower than that calculated when considering the density of the PUR foam in the air. Indeed, Mounanga et al. [11] showed that the PUR-foam density in mortar could be $5-6$ times higher than that measured in the air.

The foam porosity reduction due to the hydrostatic pressure exerted by the mortar on the PUR-foam aggregates can be approached from the foam elastic modulus, the mortar density $\rho_{\text {mortar }}$ and the 


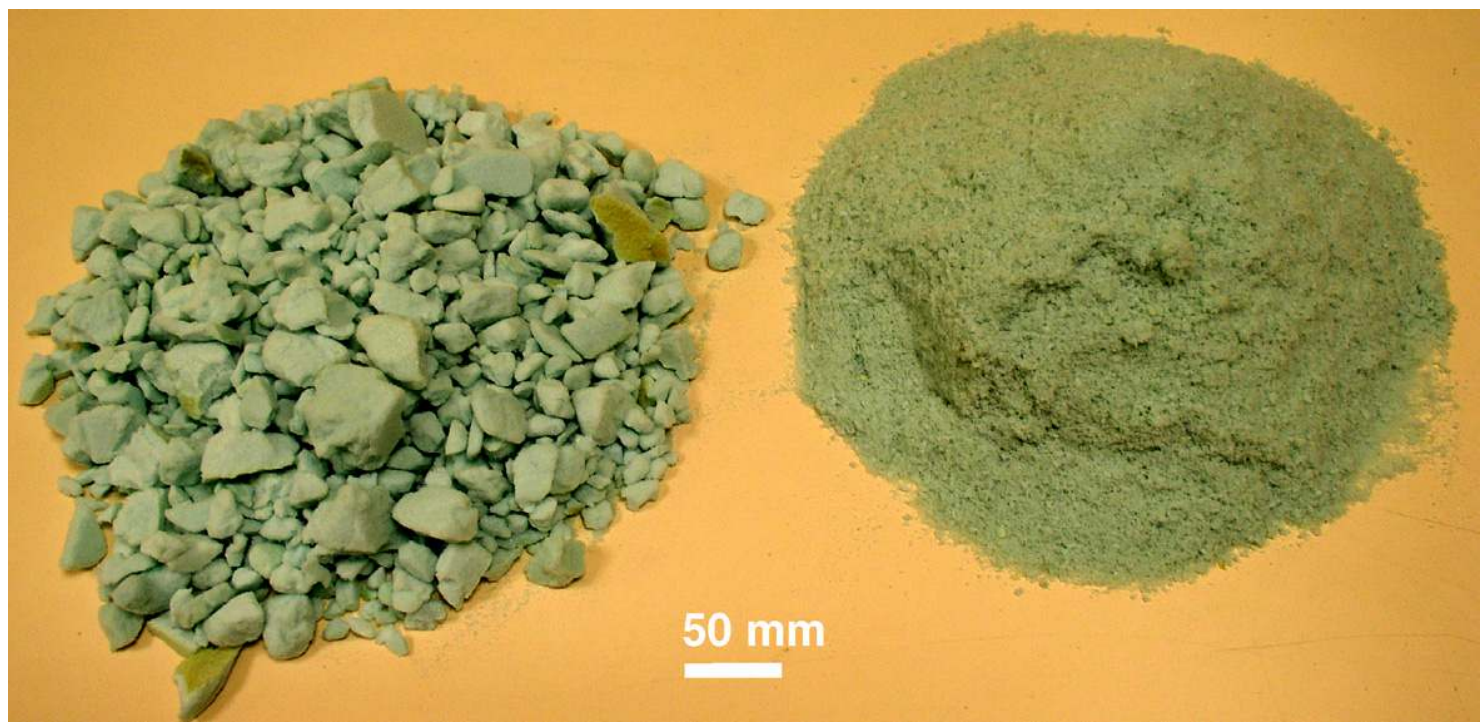

Fig. 2. PUR foam wastes (left: “coarse” aggregates, right: “fine” aggregates).

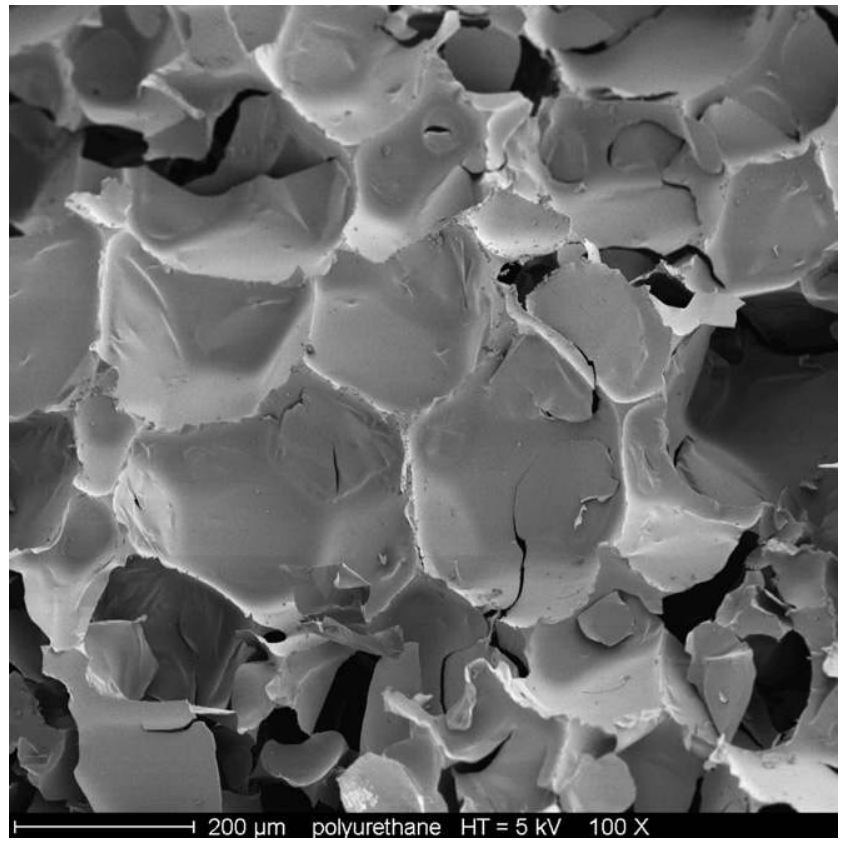

Fig. 3. SEM observation of the PUR foam waste microstructure $(\times 100)$.

height $h$ of the sample (Fig. 4). On the contrary, the cement paste penetration into the foam pores is more difficult to estimate. Zhang and Gjørv [10] observed that it depends on many parameters (open pore diameter distribution, shape and surface quality of the lightweight aggregates, etc.), which may vary according to the particle size range, and whose determination proves to be complex. Besides, the degree of compression and the paste absorption coefficient of the PUR-foam are interdependent and their effects are not easily separable: the compression of the lightweight aggregates reduces their porosity and thus their capacity to absorb paste; conversely, the paste penetration into the PUR-foam aggregates lowers the effect of the hydrostatic pressure on their volume reduction.

\subsection{Packing density of the PUR-foam concrete mixtures}

The difficulty to precisely compute the deformation of the PUR foam and the filling of its opened porosity by the paste leads to give priority to a semi-empirical approach for the prediction of the fresh PUR-foam concrete volume. First, an increase of the absolute concrete packing density is assumed to induce an augmentation in the hydrostatic pressure and thus in a greater compression of the aggregates. Secondly, compression and absorption of the lightweight aggregates tend to jointly increase the mixture packing density through the reduction in the concrete pore volume. The packing density $\gamma$ is defined as the ratio between the absolute volume $V_{\text {SoLID }}$ of the solid constituents and the measured volume $V$ of the fresh concrete:

$\gamma=\frac{V_{\text {SOLID }}}{V} \Rightarrow \gamma=\frac{1}{V} \times\left(\frac{C}{\rho_{\mathrm{C}}}+\frac{F}{\rho_{\mathrm{F}}}+\frac{\text { PUR }}{\rho_{\text {PUR }}}+\frac{S}{\rho_{\mathrm{S}}}\right)$,

where $V_{\text {SOLID }}$ is the total volume of solid constituents $\left(\mathrm{m}^{3}\right), V$ the concrete volume $\left(\mathrm{m}^{3}\right), C$ the cement mass $(\mathrm{kg}), \rho_{\mathrm{c}}$, the cement absolute density $\left(\mathrm{kg} / \mathrm{m}^{3}\right), F$, the filler mass $(\mathrm{kg}), \rho_{\mathrm{F}}$, the filler absolute density $\left(\mathrm{kg} / \mathrm{m}^{3}\right)$, PUR, the polyurethane mass (without air-voids) (kg), $\rho_{\text {PUR }}$, the polyurethane absolute density $\left(\mathrm{kg} / \mathrm{m}^{3}\right), S$ the sand mass $(\mathrm{kg})$ and $\rho_{S}$ the sand absolute density $\left(\mathrm{kg} / \mathrm{m}^{3}\right)$.

This interpretation of the phenomena led us to investigate the PUR-foam mixtures in the fresh state in order to measure the relationship between the packing and absolute densities. 60 different compositions were prepared with various water-to-cement mass ratios $W / C(W / C=0.4,0.5,0.6,0.7$ and 0.8$)$, filler-to-cement mass ratios $F / C(F / C=0.2,0.4$ and 0.45$)$, sand-to-cement mass ratios $S / C(S /$ $C=0,1,1.5,2$ and 3.5) and PUR foam-to-cement mass ratios PUR/C (PUR/C $=0.02,0.03,0.04,0.05,0.07,0.12,0.15)$. Three particle size ranges of PUR foam wastes were used: [0-2 mm], [2-5 mm] and [0-10 mm]. The bulk and packing densities of each fresh concrete were determined using pycnometer. The test results reveal a quasi-linear relationship between the packing density of the PUR-foam mixtures and their absolute density (see Section 5.1).

\subsection{Method for the estimation of the real PUR-foam concrete composition}

Deformation and absorption by the lightweight aggregates do not only modify the volume but also the composition of the manufactured concrete: the PUR-foam density increase influences the proportioning of the other components. A method to correct the initial mix-proportions is proposed in order to estimate the real fresh concrete composition. The computation method is based on the following assumptions: 
Table 2

Mix proportions of the concrete mixtures used for the thermal and mechanical tests

\begin{tabular}{|c|c|c|c|c|c|c|c|c|c|c|c|c|}
\hline \multirow[t]{2}{*}{ Series no. } & \multirow[t]{2}{*}{ Mix no. } & \multirow[t]{2}{*}{$W /(C+F)$} & \multirow[t]{2}{*}{$\mathrm{S} / \mathrm{C}$} & \multirow{2}{*}{$\begin{array}{l}\text { Volume fraction } \\
\text { of PUR foam (\%) }\end{array}$} & \multicolumn{5}{|c|}{ Mix proportions $\left(\mathrm{kg} / \mathrm{m}^{3}\right)$} & \multirow{2}{*}{$\begin{array}{l}\text { Measured density } \\
\text { of fresh concrete } \\
\left(\mathrm{kg} / \mathrm{m}^{3}\right)\end{array}$} & \multirow{2}{*}{$\begin{array}{l}\text { Density } \\
\text { increase A (-) }\end{array}$} & \multirow{2}{*}{$\begin{array}{l}\text { Mini-slump } \\
(\mathrm{mm})\end{array}$} \\
\hline & & & & & Cement & Water & $\begin{array}{l}\text { Limestone } \\
\text { filler }\end{array}$ & $\begin{array}{l}\text { PUR-foam } \\
\text { aggregate }\end{array}$ & Sand & & & \\
\hline \multirow[t]{5}{*}{ Series I } & Mix I-ref & 0.70 & 4.28 & 0 & 362 & 254 & 0 & 0 & 1549 & 2165 & 1.045 & 7 \\
\hline & Mix I-1 & 0.70 & 0.75 & 17.3 & 631 & 441 & 0 & 38 & 473 & 1583 & 0.598 & 80 \\
\hline & Mix I-2 & 0.60 & 0.75 & 17.0 & 685 & 411 & 0 & 44 & 514 & 1655 & 0.552 & 16 \\
\hline & Mix I-3 & 0.70 & 0 & 21.8 & 761 & 533 & 0 & 55 & 0 & 1349 & 0.499 & 39 \\
\hline & Mix I-4 & 0.70 & 0 & 28.2 & 699 & 489 & 0 & 73 & 0 & 1261 & 0.428 & 6 \\
\hline \multirow[t]{4}{*}{ Series II } & Mix II-ref & 0.47 & 3.75 & 0 & 382 & 261 & 174 & 0 & 1434 & 2250 & 1.009 & 70 \\
\hline & Mix II-1 & 0.81 & 2.00 & 13.1 & 357 & 422 & 162 & 23 & 714 & 1679 & 0.724 & 80 \\
\hline & Mix II-2 & 0.81 & 1.20 & 21.2 & 370 & 437 & 168 & 47 & 444 & 1467 & 0.545 & 70 \\
\hline & Mix II-3 & 0.81 & 0 & 33.7 & 395 & 467 & 180 & 58 & 0 & 1100 & 0.513 & 30 \\
\hline
\end{tabular}
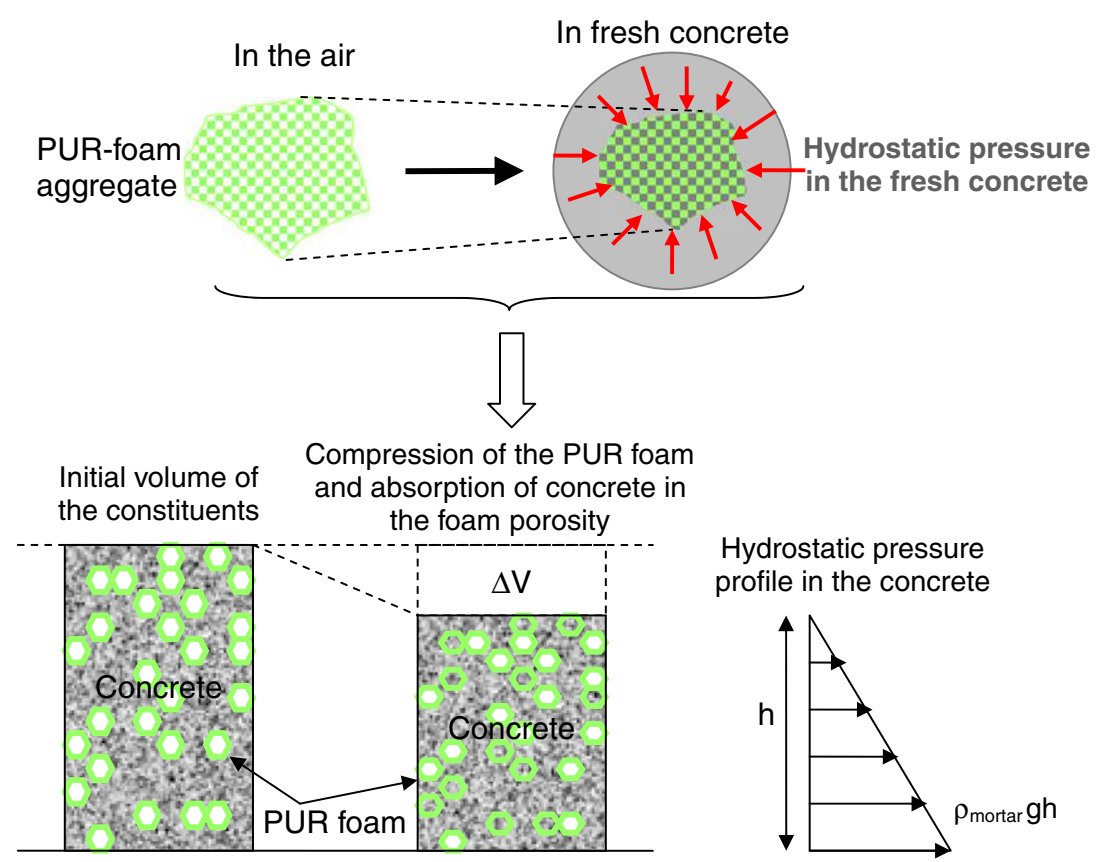

Fig. 4. Diagram of the packing of the PUR-foam concrete mixtures due to the compression and the paste absorption of the lightweight aggregates.

(i) The initial theoretical values of $W / C, S / C, F / C$ and $P U R / C$ ratios are preserved within the manufactured concrete.

(ii) Cement, filler, sand and water are regarded as incompressible phases.

(iii) Most of the air-void volume is imprisoned in the PUR-foam aggregate pores.

(iv) The positive difference observed between the measured density of the mixture and its theoretical density, is assumed to be due to the compression and the absorption of paste by PUR-foam aggregates within the mixture.

Under these assumptions, the real amount of each component (cement, filler, sand, PUR-foam aggregates and water) can be estimated using the following equation:

$[X]_{r}=\frac{[X]_{\text {th }}}{A}$,

where $[X]_{r}$ is the amount of constituent $X$ in the mixture $\left(\mathrm{kg} / \mathrm{m}^{3}\right)$, $[X]_{\text {th }}$ the initial theoretical proportion of $X\left(\mathrm{~kg} / \mathrm{m}^{3}\right), A$ the density increase of the PUR-foam concrete, i.e. the ratio of the theoretical density and of the measured density (pycnometer) in the fresh state.

The mix-proportions of the prepared PUR-foam mixtures, corrected with Eq. (3), and the value of ratio A for each mixture are given in Table 2 .

\section{Characterisation of the hardened concrete mixtures}

\subsection{Experimental program}

Two series of mixtures (Table 2) have been prepared in order to investigate the properties in the hardened state.

For the first series (Series I), the mix I-ref, without PUR foam, is regarded as a control mix: it enables to directly quantify the effect of PUR foam on the concrete properties. For mixes I-1, I-2, I-3 and $\mathrm{I}-4$, an increasing proportion of PUR-foam aggregates of class $[0-10 \mathrm{~mm}]$ is set. In addition to the influence of the PUR-foam amount, the effects of $W / C$ ratio (mix I-2), of the $S / C$ ratio (mix I3 ) and of the cement amount (mix I-4) on the lightweight concrete thermal and mechanical behaviour were studied. This first series also permits to highlight the influence of absorption and compressibility of the PUR-foam aggregates on the bulk density of fresh concrete.

For the second series (Series II), mixtures were proportioned by taking into account the experimental results about the packing density (see Section 3): the mix proportions are thus better controlled. The PUR-foam aggregates were sieved (mesh size: $5 \mathrm{~mm}$ ) beforehand, in order to eliminate the largest elements. The first mix (mix II-ref), without PUR foam, plays the role of the control 
mix. For the three PUR-foam mixtures of Series II, an increasing volume of lightweight aggregates was incorporated to progressively replace sand, maintaining close proportions of filler and cement from one mix to another (maximal variation: 6.5\%). The same W/C ratio was set for every PUR-foam mixtures: it is lower for the control mix in order to obtain a consistency of the same order of magnitude.

For each mix, the thermal properties (thermal conductivity and heat capacity), the compressive strength, the shrinkage and the mass loss due to drying were measured on prisms of $40 \mathrm{~mm} \times$ $40 \mathrm{~mm} \times 160 \mathrm{~mm}$. After mixing and casting into the moulds, the specimens were moist-cured at $20 \pm 2{ }^{\circ} \mathrm{C}$ and over $90 \%$ of relative humidity. At the end of the first $24 \mathrm{~h}$ of curing, the mixtures containing the highest fractions of PUR foam were particularly friable: this was attributed to insufficient cement hydration related to the important water amount absorbed by foam, which is, therefore, non-available for the hydration reactions. The specimens were thus kept in moist cure during $48 \mathrm{~h}$ in order to ensure a sufficient hardening for their handling. This cure was applied to the whole concrete specimens to compare their dimensional evolution considering the same moist cure period. They were then demoulded and separated into two batches: the specimens of the first batch, noted "Saturated", were immersed in a water bath at $20 \pm 1^{\circ} \mathrm{C}$, whereas the specimens of the second batch, noted "Dry", were kept in a drying chamber at controlled temperature and relative humidity $\left(T=20 \pm 2{ }^{\circ} \mathrm{C}, \mathrm{RH}=50 \pm 5 \%\right)$.

\subsection{Test procedures}

The compressive strength was measured according to the procedure of the European standard NF EN 196-1 [13]. The dimensional evolution was determined according to the French standard NF P18-427 [14]. Mass measurements were carried out using a balance with an accuracy of $0.01 \mathrm{~g}$.

The thermophysical properties were measured using the "heating film" method [15]: the boundary conditions are imposed by a heater releasing a known heating power in the sample. In our case, this heater is a paper coated with a semi-conducting graphited material (TELEDELTOS paper) subjected to an electrical potential difference $[16,17]$. The rise in temperature of the concrete prism is recorded by two thermocouples fixed on the heated face $\left(T_{\mathrm{h}}, \mathrm{h}\right.$

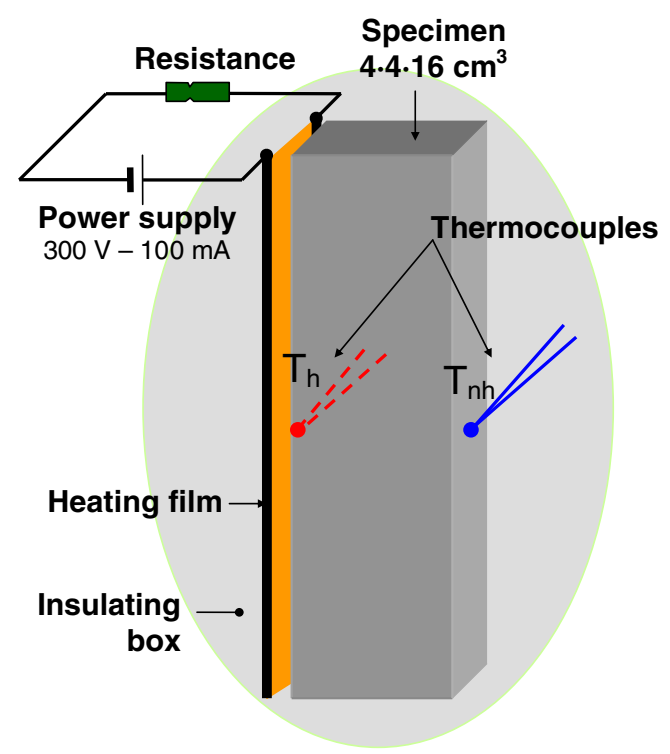

Fig. 5. Diagram of the experimental device used for the determination of the thermophysical properties of the concrete mixtures. for "heated") and on the opposite face ( $T_{\mathrm{nh}}$, nh for "non heated") (Fig. 5). The use of thermal grease, between the thermocouples and the sample faces, and of a clamping system enables to limit the effect of contact resistance. The test time is $10 \mathrm{~min}$ for each specimen. The temperature-time evolutions are post-processed using an inverse method [17] in order to determine the thermal conductivity and the heat capacity of the material.

\section{Experimental results and analysis}

\subsection{Relationship between packing density and absolute density of fresh mixtures}

As shown on Fig. 3, the pores of PUR foam are about $200 \mu \mathrm{m}$ large. This pore size is close to the diameter of the largest limestone filler and cement particles (Fig. 1). Therefore, cement paste can be absorbed by the PUR-foam aggregates. This is confirmed by video-microscopy pictures of the boundary between cementitious matrix and PUR-foam aggregates (Fig. 6). The hydrostatic pressure applied by the fresh mortar can also compress the PURfoam aggregates.

Pycnometer tests performed on 60 mixtures with various mixproportions reveal a quasi-linear relationship between the packing density and the absolute density of the concretes. As suggested on Fig. 7, this relationship is almost independent of the granular class of the PUR-foam aggregates. It is difficult to explain such a result. Nevertheless, it can be noted that the hydrostatic pressure applied by the mortar on PUR-foam aggregates, and thus their compression degree, increases with the absolute density. The packing density of concrete can be written as follows:

$\gamma=6.05 \times 10^{-4} \rho_{\mathrm{ABS}}-7.15 \times 10^{-1}$,

where $\gamma$ is the packing density (-), $\rho_{\mathrm{ABS}}$ the absolute density of concrete $\left(\mathrm{kg} / \mathrm{m}^{3}\right)$.The absolute density $\rho_{\mathrm{ABS}}$ can be calculated from the mix-proportions:

$\rho_{\mathrm{ABS}}=\frac{C+W+F+\text { PUR }}{\frac{C}{\rho_{\mathrm{C}}}+\frac{W}{\rho_{\mathrm{W}}} \frac{F}{\rho_{\mathrm{F}}}+\frac{S}{\rho_{\mathrm{S}}}+\frac{\mathrm{PUR}}{\rho_{\mathrm{PUR}}}}$

where $W$ is the water mass $(\mathrm{kg}), \rho_{\mathrm{W}}$ the water density $\left(1000 \mathrm{~kg} / \mathrm{m}^{3}\right)$.

Combining Eqs. (2) and (4), the bulk volume $V$ and the bulk density $\rho_{\text {concrete }}$ of the fresh concrete can be estimated from the mix-proportions by Eqs. (6) and (7), respectively:

$$
\begin{aligned}
& V=\frac{C}{6.05 \times 10^{-4} \rho_{\mathrm{ABS}}-7.15 \times 10^{-1}} \times\left(\frac{1}{\rho_{\mathrm{C}}}+\frac{F / C}{\rho_{\mathrm{F}}}+\frac{\mathrm{PUR} / C}{\rho_{\mathrm{PUR}}}+\frac{S / C}{\rho_{\mathrm{S}}}\right), \\
& \rho_{\text {concrete }}=\frac{6.05 \times 10^{-4} \rho_{\mathrm{ABS}}-7.15 \times 10^{-1} \times(C+W+F+S+\mathrm{PUR})}{\left(\frac{\mathrm{C}}{\rho_{\mathrm{C}}}+\frac{F}{\rho_{\mathrm{F}}}+\frac{\mathrm{PUR}}{\rho_{\mathrm{PUR}}}+\frac{s}{\rho_{\mathrm{S}}}\right)} .
\end{aligned}
$$

As shown on Fig. 8, this empirical relation permits to assess with a rather good accuracy the bulk density of mixtures proportioned with various $W / C$ ratios and various contents of cement, filler, sand and PUR-foam aggregates.

\subsection{Hardened concrete mixtures}

\subsubsection{Bulk density}

Table 3 gives the bulk density of the mixtures measured on $40 \times 40 \times 160$-mm prisms. The increase in the PUR-foam aggregate content results in a significant decrease in the bulk density. After 28 days in a room at $T=20 \pm 2{ }^{\circ} \mathrm{C}$ and $\mathrm{RH}=50 \pm 5 \%$, the density of the PUR-foam mixtures is $28-53 \%$ lower than the density of 

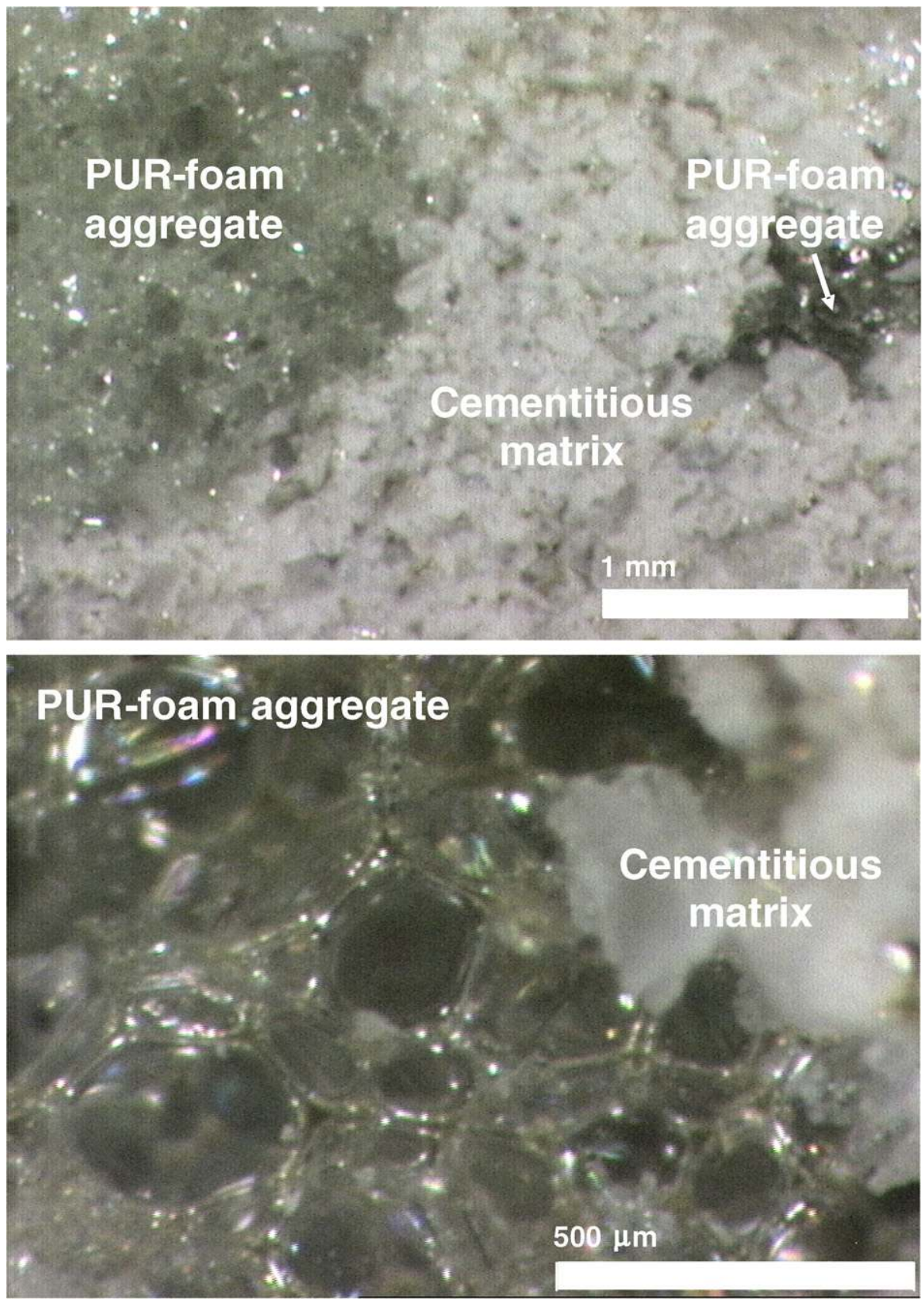

Fig. 6. Videomicroscopy observations of the interfacial zone between the cementitious matrix and the PUR-foam aggregates (Mix II-3, 33.7\% of PUR foam).

the reference mixture for the Series I - Dry and 39-63\% lower for the Series II - Dry. For mixtures immersed during 28 days in water (Series II - Saturated), the density is also much lower (25-54\%) than that of the reference mixture.

\subsubsection{Mechanical properties}

Lots of studies can be found on the mechanical properties of lightweight concrete mixtures made of polystyrene aggregates [18-20], wood shavings [21], expanded clay aggregates [9,22], etc. Contrary to usual concrete, lightweight concrete typically fails with a rupture inside the lightweight aggregates and at the boundary between aggregates and paste [23]. Wasserman and Bentur [24] observed that the use of sintered fly ash aggregates with high absorption coefficient results in higher early-age strength. The authors explain that the high water absorption reduces the water content at the interfacial zone between aggregates and paste and then makes it denser. On the contrary, Lo et al. [9,22] observed that the absorption of water by synthetic lightweight ceramic aggregates results in an increase in the interfacial zone porosity and then in a decrease in the compressive strength after 28 days. Thus, the effect of lightweight aggregates on mechanical properties seems to depend on the type of aggregates. Moreover, Laukaitis et al. [6] showed, in the case of polystyrene aggregates, that the characteristics of the boundary depend on both the aggregate size and shape.

Figs. 9 and 10 show the compressive strength of Series I - Saturated and Series II - Saturated and Dry, respectively. Each plotted value is the average of six measured values. We can observe the high decrease in the strength due to the increase in PUR foam content. The high porosity and the weak mechanical properties of the PUR foam can explain the lower strength of the lightweight concrete mixtures.

Curing under water usually improves the mechanical properties of lightweight concrete in a significant way [25]. This improvement 


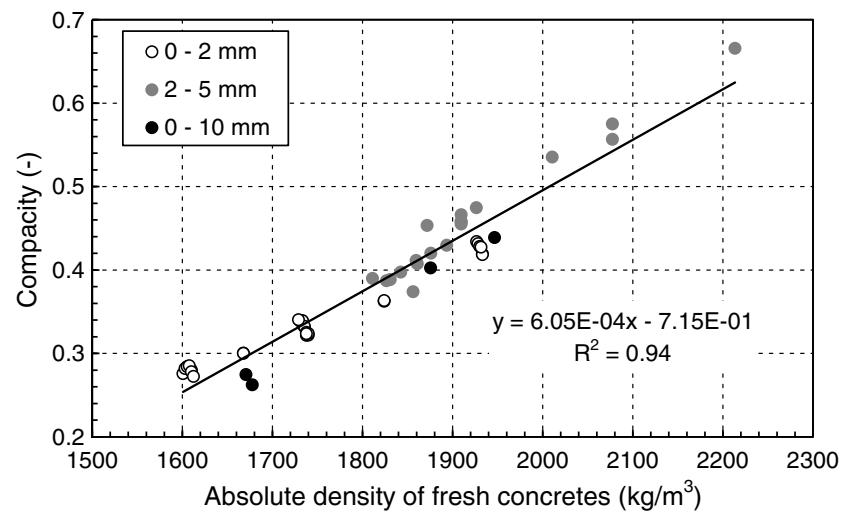

Fig. 7. Relationship between the compacity and the absolute density of various PUR-foam concrete mixtures for different granular classes of PUR-foam aggregates.

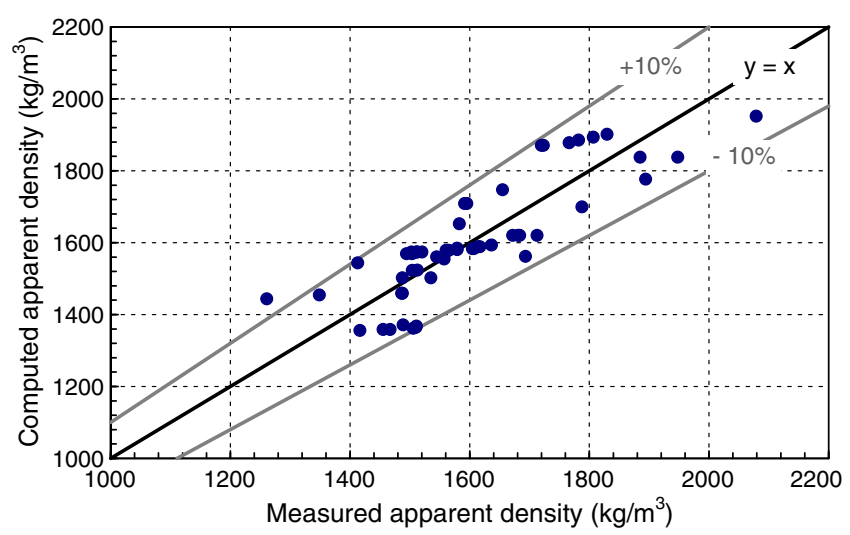

Fig. 8. Comparison between the measured apparent density of the fresh PUR-foam concrete mixtures and the bulk density computed with Eq. (7).

is often attributed to better cement hydration which increases the strength of the cementitious matrix. However, in our study, the relative increase in strength due to water curing depends on the PUR foam content (Fig. 10): the increase is equal to about $59 \%$ for the reference mixture, while it is only equal to $39 \%, 34 \%$ and $5 \%$ for the mixtures II-1, II-2 and II-3, respectively. These differences in the strength gain between the three mixtures are direct consequences of the PUR foam content, because the proportions of their matrix are about the same. It should be reminded that aggregate content, granular distribution [26] and aggregate strength [2730] are among the main parameters controlling the strength of lightweight mixtures. For the same cement content and $W / C$ ratio, a high increase in PUR foam content hides the strength improvement of the cement matrix due to water curing and therefore strongly limits the global strength improvement.

\subsubsection{Drying shrinkage and mass loss}

Kept in a climatic room at $T=20 \pm 2{ }^{\circ} \mathrm{C}$ and $\mathrm{RH}=50 \pm 5 \%$, the concrete specimens undergo drying, which is highlighted by their

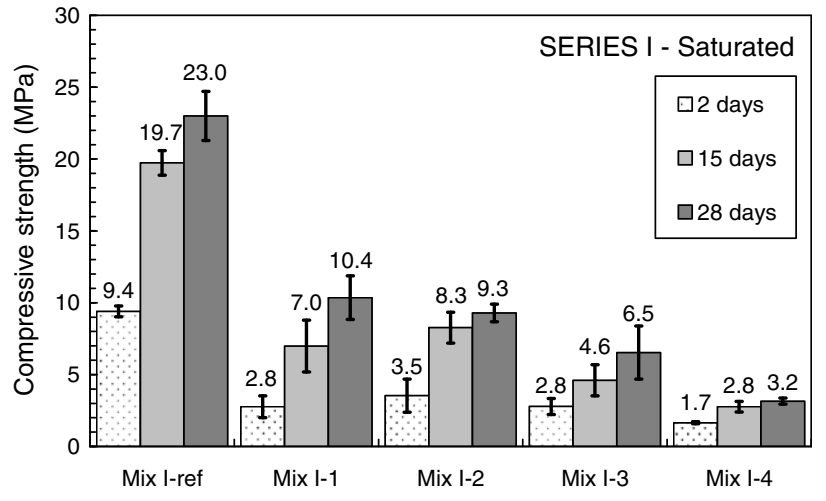

Fig. 9. Evolution of compressive strength with age (Series I - Saturated).

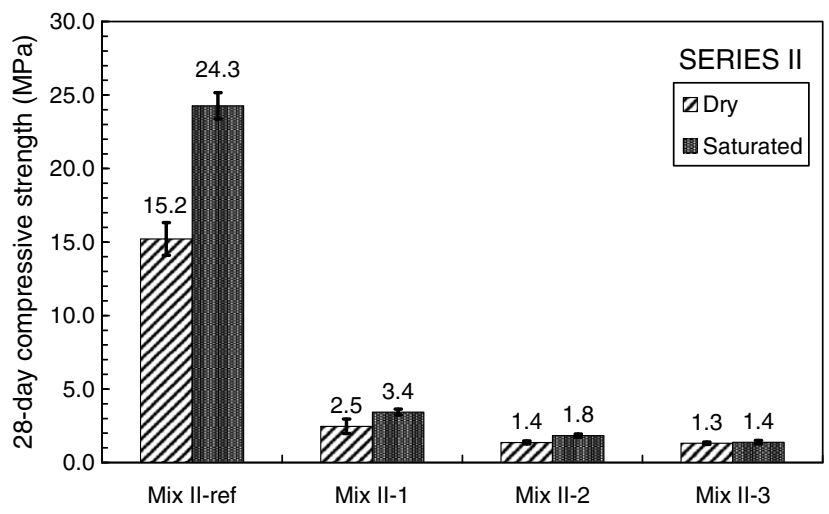

Fig. 10. Comparison of the compressive strength at 28 days in dry and saturated conditions (Series II).

mass loss (Fig. 11) and length change (Fig. 12). On Figs. 11 and 12, each curve is the average of two test results.

As shown on Fig. 11, the increase in the PUR foam content results in an increase in the mass loss. Moreover, most of drying proceeds during the first week after batching. This result is in good agreement with the study of Šelih and Bremner [31] dealing with the evolution of the water content of lightweight concrete submitted to drying between 0 and 28 days.

Since the $W / C$ ratios of our mixtures are high $(W / C>0.60)$, shrinkage can be assumed to be a consequence of drying (Table 3 and Fig. 12) [31,32]. The proportion of PUR foam influences both the rate and the final magnitude of shrinkage. The effect of PUR foam on shrinkage is mainly due to its effect on the stiffness of concrete. However, in our study, not only the PUR foam content varies but also other mix-parameters such as $W / C$ ratio and sand content (especially in Series I). These parameters are known to influence the shrinkage of concrete.

Although interactions between mix-parameters are complex, we can make the following remarks from results of Table 3 .

Table 3

Average values of drying shrinkage, mass loss and bulk density at 28 days for Series I - Dry and Series II - Dry

\begin{tabular}{|c|c|c|c|c|c|c|c|c|c|}
\hline \multirow[t]{2}{*}{ Properties at 28 days } & \multicolumn{5}{|l|}{ Series I } & \multicolumn{4}{|l|}{ Series II } \\
\hline & Mix I-ref & Mix I-1 & Mix I-2 & Mix I-3 & Mix I-4 & Mix II-ref & Mix II-1 & Mix II-2 & Mix II-3 \\
\hline Drying shrinkage $(\mu \mathrm{m} / \mathrm{m})$ & -622 & -1709 & -1427 & -2617 & -2519 & -441 & -656 & -2341 & -2016 \\
\hline Mass loss (\%) & -4.60 & -14.13 & -11.55 & -20.11 & -22.39 & -2.89 & -12.75 & -20.72 & -28.10 \\
\hline Bulk density $\left(\mathrm{kg} / \mathrm{m}^{3}\right)$ & 2109 & 1381 & 1511 & 1102 & 992 & 1952 & 1196 & 982 & 728 \\
\hline
\end{tabular}




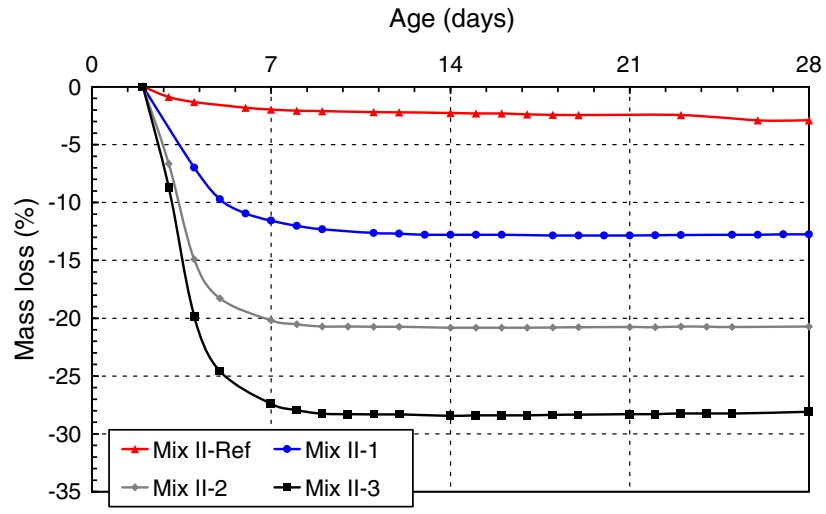

Fig. 11. Mass loss of the PUR-foam concrete mixtures $\left(T=20 \pm 2{ }^{\circ} \mathrm{C} ; \mathrm{RH}=50 \pm 5 \%\right)$.

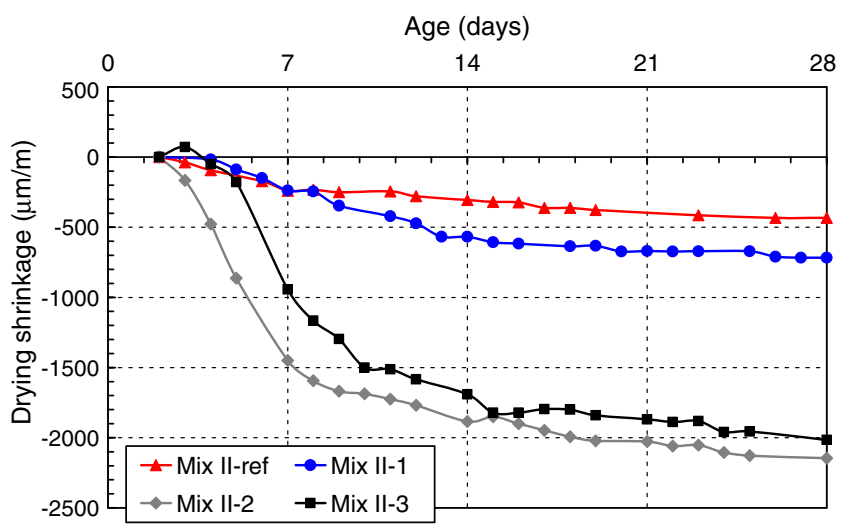

Fig. 12. Drying shrinkage of the PUR-foam concrete mixtures $\left(T=20 \pm 2{ }^{\circ} \mathrm{C}\right.$; $\mathrm{RH}=50 \pm 5 \%)$.

- The decrease in $W / C$ ratio leads to a decrease in the shrinkage magnitude at 28 days.

- The mixtures with the highest PUR foam amount, i.e. mixes I-4 and II-3, have not necessarily the highest shrinkage amplitude. Note that these mixtures do not contain sand.

- In the case of mixtures containing sand, the increase in PUR foam proportion results in a higher shrinkage magnitude.

For the mixtures designed without sand, mixes I-3 and I-4 [11] and mix II-3 (Fig. 12), the measured length change during the first $48 \mathrm{~h}$ is due to dilation. This volume increase could result from dilation of the PUR foam due to water absorption. It could also be of thermal origin, since the cement content is high, in particular in the case of mixes I-3 and I-4 (Table 2). Moreover, as shown in the followings (Section 5.3), high PUR foam content decreases the thermal conductivity; the hydration heat should be dissipated more slowly and could induce higher temperature rise and thermal dilation. This thermal dilation could explain the fact that the mixtures with the highest PUR foam contents (mixes I-3 and I-4) have not the highest shrinkage magnitude at 28 days.

Finally, it must be emphasized that any conclusion on drying shrinkage should be done carefully. Actually, the measured shrinkage includes the effect of skin cracking due to water content gradient between the skin and the core of the prism [33]. Besides, shrinkage is not the only relevant parameter controlling the cracking potential of concrete, since it also depends on visco-elastic and fracture properties.

\subsection{Thermophysical properties}

Table 4 shows the values of the thermal conductivity and volumetric heat capacity for the mixtures from Series I and II. Each value is the average of results obtained on three different specimens of the same batch.

The incorporation of lightweight aggregates in concrete generally yields quite a strong decrease in the concrete thermal conductivity. This decrease is due to the important porosity of lightweight aggregates $[21,34,35]$. Their pores contain air whose thermal conductivity is much lower than that of the other constituents. Table 4 shows that it is possible to diminish the thermal conductivity by varying the PUR foam content. A diminution in a ratio of 2.5-4.6 for Series-I specimens and in a ratio of 2.2-6.8 for Series-II specimens has been observed. This ratio has to be understood as compared with the conductivity of the reference concrete. This decrease is less important for the saturated specimens, but it is still sensitive: for Series I - Saturated, the same ratio ranges from 1.9 to 3.4. This ratio ranges between 2 and 4.3 for Series II - Saturated.

The influence of PUR foam on the volumetric heat capacity is less significant. The heat capacity of one mixture is the volume fraction-weighted average of the different compounds heat capacity [36]. In the dry state, the low heat capacity of PUR foam yields a decrease in the PUR-foam concrete heat capacity as compared with that of the reference concrete (15-29\% for Series I - Dry and 18$44 \%$ for Series II - Dry; see Table 4). For saturated specimens, the results are different: the PUR-foam concrete heat capacity is greater than that of the reference concrete and increases with the foam content. Indeed, the pores of the specimens kept in water during 28 days are filled with water, whose heat capacity is particularly high in comparison with that of the other solid elements [37]. For saturated samples, the higher the foam volume fraction, the higher the volume filled with water and the higher the volumetric heat capacity (Table 4 ).

\section{Conclusions and further work}

This study shows that it is possible to manufacture lightweight concrete of plastic consistency using rigid polyurethane (PUR)

Table 4

28-day thermophysical properties of the PUR-foam concrete mixtures (average value \pm standard deviation)

\begin{tabular}{|c|c|c|c|c|c|}
\hline \multirow[t]{2}{*}{ Serie no. } & \multirow[t]{2}{*}{ Mix no. } & \multicolumn{2}{|c|}{ Thermal conductivity (W/m K) } & \multicolumn{2}{|c|}{ Heat capacity $\left(\mathrm{MJ} / \mathrm{m}^{3} \mathrm{~K}\right)$} \\
\hline & & Dry & Saturated & Dry & Saturated \\
\hline \multirow[t]{5}{*}{ Series I } & Mix I-ref & $1.44 \pm 0.10$ & $2.34 \pm 0.06$ & $1.95 \pm 0.05$ & $2.72 \pm 0.17$ \\
\hline & Mix I-1 & $0.55 \pm 0.01$ & $1.12 \pm 0.07$ & $1.56 \pm 0.02$ & $3.17 \pm 0.06$ \\
\hline & Mix I-2 & $0.58 \pm 0.04$ & $1.24 \pm 0.01$ & $1.65 \pm 0.03$ & $3.16 \pm 0.03$ \\
\hline & Mix I-3 & $0.31 \pm 0.02$ & $0.78 \pm 0.04$ & $1.38 \pm 0.08$ & $3.47 \pm 0.02$ \\
\hline & Mix I-4 & $0.31 \pm 0.04$ & $0.68 \pm 0.07$ & $1.38 \pm 0.15$ & $3.22 \pm 0.06$ \\
\hline \multirow[t]{4}{*}{ Series II } & Mix II-ref & $1.49 \pm 0.16$ & $2.60 \pm 0.09$ & $1.92 \pm 0.12$ & $2.78 \pm 0.05$ \\
\hline & Mix II-1 & $0.67 \pm 0.02$ & $1.33 \pm 0.11$ & $1.58 \pm 0.06$ & $2.88 \pm 0.13$ \\
\hline & Mix II-2 & $0.32 \pm 0.00$ & $1.04 \pm 0.04$ & $1.24 \pm 0.03$ & $3.05 \pm 0.15$ \\
\hline & Mix II-3 & $0.22 \pm 0.01$ & $0.60 \pm 0.02$ & $1.08 \pm 0.03$ & $2.99 \pm 0.12$ \\
\hline
\end{tabular}


foam wastes. The main difficulty to proportion such concrete mixtures lies in the estimation of the PUR foam density, which is greatly influenced by both the high compressibility and absorption of the lightweight aggregates (compared with the traditional components of concrete). The experimental investigation on various fresh PUR-foam mixtures revealed a linear correlation between their packing density and their absolute density in the fresh state. This correlation was used to prepare lightweight concrete mixtures containing, in volume fraction, between $13 \%$ and $34 \%$ of PUR-foam aggregates.

The thermal conductivity of the lightweight concrete mixtures in the hardened state ranges between 0.22 and $0.67 \mathrm{~W} / \mathrm{m} \mathrm{K}$ for the dry specimens and between 0.60 and $1.33 \mathrm{~W} / \mathrm{m} \mathrm{K}$ for the specimens cured under water. The density of these mixtures is $25-63 \%$ lower as compared to that of the reference mixtures (without PURfoam aggregates). These performances are mainly due to the high porosity of lightweight aggregates. That induces a drying shrinkage 4-5 times more important as compared with the control specimens and a lower mechanical resistance, ranging between 1.3 $\mathrm{MPa}$ and 10.4 MPa.

Future work will focus on the improvement of the mechanical properties of the PUR-foam concrete mixtures by using cement of type I and reactive mineral additions (blast furnace slag, silica fume or fly ash), instead of limestone filler. The incorporation of synthetic fibres and shrinkage reducing admixtures is also a possible research way to extend the potential application of these mixtures to the field of repair materials. Finally, it will be interesting to measure the effect of the utilization of coarser PUR-foam aggregates on the thermal and mechanical properties of concrete in order to propose an alternative option to dispose the whole of the particle size ranges of PUR foam wastes.

\section{Acknowledgement}

The authors wish to thank Mrs. Annick Perronnet, of Laboratory GeM, UMR CNRS 6183 (research team "Mechanical State and Microstructure") for the realization of the SEM tests.

\section{References}

[1] Zevenhoven R. Treatment and disposal of polyurethane wastes: options for recovery and recycling. Report TKK-ENY-19, Helsinki University of Technology, Department of Mechanical Engineering, Energy Engineering and Environmental Protection Publications; 2004.

[2] ISOPA. Fact sheet on Recycling and recovering polyurethanes: options in practise; 2005. <http://www.isopa.org>.

[3] Hilyard NC, Kinder AI, Axelby GL. A techno-economic study of the disposal of polyurethane foam waste by incineration and heat recovery. Cell Polym 1985;4(5):367-84

[4] Gutt W, Nixon PJ. Use of waste materials in the construction industry. Mater Struct 1979;12(4):255-306.

[5] Boser R, Ragsdale T, Duvel C. Recycled foam and cement composites in insulating concrete forms. J Ind Technol 2002;18(3):1-5. Available from: $<$ http://www.nait.org>.

[6] Laukaitis A, Žurauskas R, Kerienè J. The effect of foam polystyrene granules on cement composite properties. Cement Concrete Compos 2005;27(1):41-7.

[7] Perevozchikov A, Yakovlev G, Kodolov V. Polyethylene foam waste utilization for light-weight concrete production. Int J Polym Mater 2000;47(1):7-17.

[8] Müller-Rochholz J. Investigation of the absorption of water by lightweight aggregate from cement paste. Int J Cement Compos Lightweight Concrete 1979;1(1):39-41.

[9] Lo TY, Cui HZ, Tang WC, Leung WM. The effect of aggregate absorption on pore area at interfacial zone of lightweight concrete. Construct Build Mater, in press., doi: 10.1016/i.conbuildmat.2006.10.011.
[10] Zhang M-H, Gjørv Odd E. Penetration of cement paste into lightweight aggregate. Cement Concrete Res 1992;22(1):47-55.

[11] Mounanga P, Turcry P, Poullain P. Thermal and mechanical effects of the incorporation of polyurethane foam wastes in a mortar. 24th University meetings of Civil Engineering, "Building: a new challenge", La Grande Motte (France); 2006 [in French].

[12] NF EN 18-560. Aggregates. Particle size distribution by sieving. French standards, AFNOR editions; 1990.

[13] NF EN 196-1. Methods of testing cement - Part 1: Determination of strength European standards, AFNOR editions; 2006.

[14] NF P18-427. Determination of the dimensional variations between two opposite faces of hardened test specimen concrete. French standards, AFNOR editions; 1996.

[15] Bastian G. Determining the thermophysical properties of construction materials by the plane source method in transitory and asymptotic regime. Rev Phys Appl 1987;22:431-44 [in French].

[16] Mounanga P, Bastian G, Bron G, Coué R. Rapid determination of the thermophysical properties of various materials. Method of the hot plane film. EurPhys J - Appl Phys 2004;26(1):65-72.

[17] Poullain P, Mounanga P, Bastian G, Coué R. Determination of the thermophysical properties of evolutive porous media: application to civil engineering materials. Eur Phys J - Appl Phys 2006;33(1):35-49.

[18] Ganesh Babu K, Saradhi Babu D. Performance of fly ash concretes containing lightweight EPS aggregates. Cement Concrete Compos 2004;26(6):605-11.

[19] Saradhi Babu D, Ganesh Babu K, Wee TH. Properties of lightweight expanded polystyrene aggregate concretes containing fly ash. Cement Concrete Res 2005;35(6):1218-23.

[20] Miled K, Sab K, Le Roy R. Particle size effect on EPS lightweight concrete compressive strength: experimental investigation and modelling. Mech Mater 2007;39(3):222-40.

[21] Bederina M, Marmoret L, Mezreb K, Khenfer MM, Bali A, Quéneudec M Effect of the addition of wood shavings on thermal conductivity of sand concretes: experimental study and modelling. Construct Build Mater 2007;21(3):662-8.

[22] Lo TY, Tang WC, Cui HZ. The effects of aggregate properties on lightweight concrete. Build Environ 2007;42(8):3025-9.

[23] Lijiu W, Shuzhong Z, Guofan Z. Investigation of the mix ratio design of lightweight aggregate concrete. Cement Concrete Res 2005;35(5):931-5.

[24] Wasserman R, Bentur A. Interfacial interactions in lightweight aggregate concretes and their influence on the concrete strength. Cement Concrete Compos 1996;18(1):67-76.

[25] Haque MN, Al-Khaiat H, Kayali O. Strength and durability of lightweight concrete. Cement Concrete Compos 2004;26(4):307-14.

[26] Le Roy R, Parant E, Boulay C. Taking into account the inclusions' size in lightweight concrete compressive strength prediction. Cement Concrete Res 2005;35(4):770-5.

[27] Nilsen AU, Monteiro PJM, Gjørv OE. Estimation of the elastic moduli of lightweight aggregate. Cement Concrete Res 1995;25(2):276-80.

[28] Chi JM, Huang R, Yang CC, Chang JJ. Effect of aggregate properties on the strength and stiffness of lightweight concrete. Cement Concrete Compos 2003;25(2):197-205.

[29] Husem M. The effects of bond strengths between lightweight and ordinary aggregate-mortar, aggregate-cement paste on the mechanical properties of concrete. Mater Sci Eng A 2003;363(1-2):152-8.

[30] Saradhi Babu D, Ganesh Babu K, Wee TH. Effect of polystyrene aggregate size on strength and moisture migration characteristics of lightweight concrete. Cement Concrete Compos 2006;28(6):520-7.

[31] Šelih J, Bremner TW. Drying of saturated lightweight concrete: an experimental investigation. Mater Struct 1996;29(7):401-5.

[32] Zhang M-H, Lian L, Paramasivam P. Shrinkage of high-strength lightweight aggregate concrete exposed to dry environment. ACI Mater J 2005;102(2): 86-92.

[33] Turcry P, Loukili A, Rozière E. Influence of the substitution of cement by mineral addition on the cracking risk of self-compacting concretes discussion on the interpretation of drying shrinkage measurements. National conference on transfer "Transfert 2006", Lille (France); 2006 [in French].

[34] Demirboğa R, Gül R. The effects of expanded perlite aggregate, silica fume and fly ash on the thermal conductivity of lightweight concrete. Cement Concrete Res 2003;33(5):723-7.

[35] Ünal O, Uygunoğlu T, Yildiz A. Investigation of properties of low-strength lightweight concrete for thermal insulation. Build Environ 2007;42(2): 584-90.

[36] Farouki OT. Thermal properties of soils, series on rock and soil mechanics, vol. 11. Clausthal-Zellerfeld: Trans Tech Publications; 1986.

[37] Bentz DP, Waller V, de Larrard F. Predicting of adiabatic temperature rise in conventional and high-performance concretes using a 3D microstructural model. Cement Concrete Res 1998;28(2):285-97. 